\title{
The Role of Personal Values and Empathy in a Cooperative Game
}

\author{
Jie-Yu LV, Michael, J.Proulx, Magda Osman
}

Biological and Experimental Psychology, Queen Mary Unversity of London, Mile End Road, London, E1 4NS j.lv@qmul.ac.uk

Department of Psychology, University of Bath, BA2 7AY, UK

m.j.proulx@bath.ac.uk

Biological and Experimental Psychology, Queen Mary Unversity of London, Mile End Road, London, E1 4NS

\section{ABSTRACT}

m.osman@qmul.ac.uk

Are the personal values of others a relevant cue when thinking about cooperating, and do values matter more than empathizing with others? To address these questions, the present study presented participants $(N=120)$ with the details of personal values (social values [e.g., family, friends] or economic values [e.g., phone, bike]) held by fictitious players of a linear public goods game (PGG). In addition, half those tested were induced to empathize with the other players via presenting perspective-taking instructions (empathy induction), and the other half were not. For those that believed they were interacting with real players in a cooperative game $(n=70)$ values did indeed matter. Participants acted more cooperatively in the Social Value condition as compared to the Economic Value condition when there was empathy induction. While empathy induction (perspective-taking instructions) made little difference to levels of cooperation, it did reduce the use of the tit-for-tat strategy in the game. These findings present some challenges to recent work promoting the role of empathy in pro-social behaviors.

\section{Keywords}

Empathy, Cooperation, Value, Public Goods Game (PGG), tit-for-tat strategy

\section{Academic Discipline And Sub-Disciplines}

Psychology; Social Psychology

\section{SUBJECT CLASSIFICATION}

Social Science

\section{TYPE (METHOD/APPROACH)}

Empirical Laboratory Experiments

\section{Council for Innovative Research}

\author{
Peer Review Research Publishing System
}

Journal: Journal of Social Sciences Research

Vol. 9, No. 2

jssreditor.cir@gmail.com

www.jssronline.com 


\section{INTRODUCTION}

As the most frequent prosocial behavior (1), cooperation is a

Iso one of the most investigated topics in social psychology. Its prevalence is also an indication of the necessary function it serves in maintaining social interactions, from the micro-level, as seen in small-scale networks (2)to macro-levels, as observed in interactions between whole societies (3). Typically cooperation is thought of as occurring in actual face-to-face social interactions; given the shift to conducting many day to day activities online (for business and leisure), cooperation is ever more present in the virtual world too (4). For instance, many more business interactions involve negotiations and investment decisions taking place online (e.g., Google Hangout, Skype) (5). Therefore, one of the aims of the present study is to examine potential cues in the social environment that can likely impact cooperative behaviors in non-face-toface interactions instead of traditional face-to-face interactions.

Traditionally, studies examining cooperation in the experimental lab typically involve economic games such as two -player games (e.g., prisoner's dilemma (6), ultimatum game $(7,8)$ and multi-player games with 4 or more players (e.g., public goods game (PGG) $(9,10)$ and the common resource dilemma $(11,12)$. Many of these tasks present participants with a dilemma in which they can choose to perform a selfish but economically beneficial action, or cooperate with another, but gain less financially. In each game, there is a best strategy to solve these problems. Given the pay-off structure, from a standard rational choice perspective, the best strategy in the prisoner's dilemma is to defect rather than cooperate (13). However, when playing multiple rounds, people typically employ a tit-for-tat strategy (14); this is strictly a reciprocal strategy in that the previous behavior of an individual is always matched during the next round by the other players (15, 16). In a multi-player version of the prisoner's dilemma, such as the PGG, the rational choice for the collective is to cooperate; but for individuals, the best strategy is to defect regardless of what the other players do (13). In a typical PGG, players are endowed with 20 tokens on each of 10 rounds, and on each round they have to choose how many tokens they would like to contribute to the group pot. The money in the group pot on each round gets multiplied by a small amount (smaller than $\mathrm{N}$, larger than 1), and the total gets shared between all players regardless of the amount of tokens they contributed to the group pot. If All players contribute all tokens to contribute to the group pot, everyone gets more than if everyone all contribute 0 . But if one player contributes 0 (free rider) and the others contribute all their tokens, the free rider gets the highest payoff and the others get the lowest. It is in each person's interest to contribu te nothing into the group pot, even though all would be better off had they cooperated. So, in a one-shot PGG, it is individually optimal to contribute nothing, and socially optimal to contribute all tokens into the group pot. Cooperation here is the behaviour of contributing money to the group pot. Cooperation also reflects a risky decision because there is no way of knowing in advance whether anyone else will contribute, and how much they will contribute. By extension, defection indicates risk aversion, as well as non-prosocial behavior; this is because this strategy guarantees a set return on each round (20 tokens), while also reaping the return from the shared pot. As with the prisoner's dilemma, across rounds in the PGG people learn to adopt the most common strategy, which is tit-for-tat. According to Fehr and Fischbacher(13), the prisoner's dilemma is a PGG but with two players, and in both games each player has only two actions: cooperation or defection. Also, in both games each player has an economic incentive to deviate from mutual cooperation by consuming the public good by letting the other player(s) pay for it.

The tit-for-tat strategy is an efficient way to play multi-player iterative games (prisoners' dilemma, PGG); this is because simply matching the behavior of the other player(s) doesn't involve developing an independent strategy of one's own, which is also why it is considered a selfish strategy (17). It is also not a strategy that consistently advances cooperation, unless the other player(s) consistently cooperate. One way in which to promote cooperative behaviors in economic games such as prisoner's dilemma and PGG is by enabling players to communicate task relevant information to each other (18). In fact, task-relevant communication is thought to be a way of promoting cooperation because it helps signal interpersonal noms related to fairness and trust (19) that in turn encourages players to conform to these noms and behave prosocially. In addition, increasing trust amongst players in turn increases cooperation in the PGG (20), as does increasing empathy towards other players by knowing about personal experiences of suffering $(6,21,22)$.

Taken together, the evidence from studies promoting cooperation supports several social cognition theories of cooperation in social dilemmas. According to Parks' Integrated Model (23), which is adapted from the Interdependence Theory (24), people pay attention to two key factors when deciding to cooperate in social dilemmas. They focus on the outcomes from decisions made in a social situation (e.g., rewards, punishments) and the social properties within the situation (e.g., trus tworthy signals, opportunities to communicate). Retuming to non-face-to-face social interactions, such as those online, we also find evidence in support of Park's et al (2013) theory. Signaling trustworthiness through reputation and communication appears to impact strongly on increasing cooperation, regardless of whether the social interactions occurs live or in a virtual context (25).

Based on the Empathy-Altruism Hypothesis(26), empathy plays an important role in modulating cooperation. This is because people use an "other-oriented" emotional response congruent with the perceived welfare of another from which to base their decision to cooperate(6). However, the mediating role of empathy appears to be sensitive to the type of context in which the social interaction takes place. Typically, demonstrations in which empathy induction increases cooperation are dependent on focusing empathetic emotions towards a specific individual, and this is done face-to-face (27).

Therefore, in the present study, our first objective is to consider whether empathy has a moderating role in inducing cooperation in a non-face-to-face social dilemma, particularly in a multi-player game. Previous research exam ining the link between empathy and cooperation has mainly concentrated on the prisoner's dilemma $(6,21,28)$. If empathy is indeed dependent on face-to-face interactions with others that are physically present, then we would expect that it would have a limited role in increasing cooperation in a non-face-to-face context in an iterated PGG. Besides, providing perspectivetaking instruction is the way of educating others to care for others, a solution for promoting cooperation (17), which is able to be examined its validity by our experiment.

The second objective of the present study is to examine the impact of other cues on cooperation, in particular the role of personal values in cooperative behavior. Values are commonly considered as "relatively stable individual preferences 
about desirable states and behavior that reflects socialization" (29). In addition, personal values consist of social, economic, theoretical, aesthetic, political and religious values (30). A large body of research has demonstrated that there is a strong relationship between people's personal values and their personality type, as well as the decision-making strategies they implement $(29,31,32)$.Bardi and Schwartz (33) speculate that identifying personal values could be used as a way to gauge the extent to which people will behave well socially. For example, providing information about one content domain of values (e.g., religiosity (34)) influenced corresponding relevant behavior in another domain. Also, in reference to the connection between values and cooperation, some researchers have focused on the role of cultural values on cooperative behaviors (35). In addition, a highly influential body of research has shown an association between individual difference, based on personal values (specifically Social Value Orientation (SVO) involved 'individualists' or 'prosoicals' (36)), and levels of cooperation (37, 38). In contrast, few studies considered values information as cues to affect individuals' cooperative decision making. There are few studies that have examined a direct association between personal values as contextual cues and cooperation in social dilemmas. For instance, Volk, Thöni, and Ruigrok(39) measured the extent to which personal values were associated with levels of cooperation. Volk et al. (39)found individuals that highly valued prosocial values (e.g. equality) were more likely to cooperate than free-ride. If the types of personal values signal pro-sociality, as implied by various studies that provide indirect evidence of a link between values and cooperation, then we would expect that manipulating the types of values (economic - i.e. selfish, social - i.e. pro-social) shared by a group would impact on cooperative behavior in social dilemmas. Taken together, given that this is an underexplored issue in studies of cooperation, the aim of the present is to provide new insights into understanding the role of personal values on cooperative behaviors.

In our version of the PGG, there are three virtual players and only one real participant involved in each experimental set up. The reason for using fictional players was to allow for careful control the range of empathic experiences that would impact on the real participants' behavior during the PGG. Nevertheless to keep the experimental set up as close to real as possible, the contributions that the virtual players' made, though pre-programmed, were based on data obtained in a real four player PGG experiment (9). While this is not a perfect setting to examine cooperative behavior in a PGG game, it one of the most efficient experimental designs to control for factors regarding empathy and values, on cooperative behaviors in the PGG. Experimental designs such as the one adopted in the present study involve a critical issue regarding "interaction deception"; this means participants are deceived into believing that they are interacting with genuine participants. Typicall y what is done is that several participants are placed into the same room and play a game at the same time, to give the illusion they are actually interacting with the others in the room, but in actual fact they are not (40). In other cases, studies used programmed strategy or predesign strategies to mimic real players while participants played a prisoner's dilemma games $(6,21,22)$. Similarly, Kurzban and Houser $(41)$ us ed a predesigned 10 -round PGG in order to create a realistic setup for participants; this also involved interactive deception. Moreover, the research on tit-for-tat strategy and proof of its success as a strategy is often explored using computer tournaments (15). Thus, the experimental design used presently makes it possible to validly measure the role of empathy and cooperation. However, one critical difference between these past studies and the present study, is that we include a measure of awareness of "intera ction deception", moreover we will use this measure to gauge the extent to which it differentially impacts on cooperative behavior in an iterative PGG.

\section{Present study}

In sum, the aim of the present study is to examine two unexplored issues in the domain of cooperation. First, we examine whether empathy induction is dependent on live face-to-face interactions by inducing participants to empathize with three virtual players in an online PGG. Second, we also examine the role of the types of values shared on co operative behaviors in a PGG. If personal values serve as cues to cooperation, which people use to inform their decisions to cooperation (23, 42), then when the group shares values that are social values we expect this to lead to higher levels of cooperation than when the group shares economic values. In our studies, values were signalled through stories of suffer in which the cause of suffering was social or material. To best of our knowledge, the present study is the first attempt to explore the role of personal value through this method to examine the impact of values on cooperation. Based on prior work, we predict that social value information will promote people to behave more cooperatively than those conveying economic value signs. In addition, given the design we used, we also aim to explore the impact of interactive deception on cooperative behavior. The objective here is to provide important insights regarding work that adopts similar methodologies that lead to interactive deception, but that have yet to examine the behavioral impact of this method.

\section{METHOD}

\section{Participants}

Our experiment included 120 participants (80 female and 40 male) in four groups of 30 . Participants were recruited from Queen Mary University of London via email announcements and pos ted fliers. Participants were aged between 18 to 49 $(M=22.09, S D=4.94)$. They provide informed consent prior to participation. On completion of the experiment, participants received between $£ 6$ and $£ 15$ based on their performance in the linear PGG $(25$ tokens $=£ 1)$. When debriefed, all participants were asked whether they believed they were interacting with three other players online. Forty-nine participants reported they did not believe they were interacting with three other real players, and one participant reported that he was not sure about that. The Ethics Committee of Queen Mary University of London approved this research study.

\section{Design and Materials}

This experiment was a $2 \times 2$ (Value [Social Value, Economic Value] $\times$ Empathy [Empathy, No Empathy]) betweensubjects design, and participants were randomly allocated to one of the four experimental conditions. The critical dependent variable was the number of tokens participants contributed to the common pot on each of the 10 rounds, which is also the operational definition of cooperation in such economic games. 
In addition, we recorded other details in a set of questions given before and after the study. The pre-questions included questions on personal information regarding age and gender, and questions concerning the participant's positive and negative experience over the past year. Moreover, participants were presented with Interpersonal Reactivity Index (IRI) (43)questionnaire which is used to measure their dispositional empathizing ability, and consists of four subscales, perspective taking (PT), empathic concem (EC), personal distress (PD) and fantasy (FT). The participant's photo was taken using a phone camera that was uploaded on screen along with photos of the three virtual players; these steps were designed so that participants believed they followed the same procedures as the other three players they were interacting with online. The reasons for using virtual rather than real players was to allow for careful manipulations of the range of values of the other players and the personal histories of their experiences, and the impact it would have on the participants behavior during the PGG. The three other player photos and their profiles were made in advance, and piloted. The details of the profiles were based on a published value survey (44). The most common values were predominately nonmaterialistic which formed the Social Value condition (e.g., family, friends, health; $86 \%, 45 \%$ and $30 \%$, respectively), and the least common values were predominately materialistic (e.g., mobile phone, bicycle, pet; $3 \%, 3 \%, 3 \%$, respectively), which formed the Economic Value condition. The profiles of the three virtual players were matched on the basis of number of words of the personal events. Below is the profile from a virtual player in the Social Value condition in which theme was friend:

I speak to my best friend nearly every day. She is the closest person to me outside of my family. Recently we fell out. This isn't the first time that this has happened, and I know that we can fix this, but it is still upsetting.

Below is the profile from a virtual player in the Economic Value condition in which the theme is phone:

I speak on my mobile phone nearly every day. It is the object most close to me other than my laptop. Recently I broke my phone. It fell out of my bag. This isn't the first time that this has happened, and I know that I can fix this, but it is still upsetting.

The PGG was carried out via a computer using E-prime 2.0. In the PGG program, the number of tokens the three players contributed on each round was fixed, and the same for each participant. The number and variance in the tokens contributed was based on Fehr and Gächterstudy's(9) using average contributions (taking into account the standard deviation) in their partner-treatment without punishment condition. The combined total contribution of the three other players on each round was as follows: $27,34,31,24,22,23,24,18,12$ and 10.

The post-questions recorded participants' impression towards the three other virtual players on a 9-point scale, ranged from 1 (not at all) to 9 (very much), based on the extent to which they empathized with each of them. In addition, participants were also required to rate, on the same 9-point scale, the extent to which their personal values related to those of each of the three other players.

During the debriefing session participants were asked if they thought they were interacting with real players online or not, whether they knew the other players, and what strategies, and were then debriefed about the experimental set up.

\section{Procedure}

Each participant was tested individually in a soundproofed experimental cubicle facing a computer monitor. After signing the consent form and reading the information sheet, participants filled in the pre-questions, and their photos were taken. Participants were then asked to wait for approximately 5 minutes and were told that this time was needed to coordinate the other players that were taking part in the experiment, where the interaction deception was involved. During this time participants were told to carefully read the instructions for PGG.

Before participants took part in the PGG task, they were presented with their own picture, alongside the three other players' pictures and were told that they were playing the game with these three people. Then the Empathy condition was presented with the empathy induction procedure. They were told: "Next you will see profiles of the three other participants who will work together with you. While you are reading this, try to imagine how the person felt about what they have just described. Try to imagine how it has affected them and how they feel as a result". In the No Empathy condition, they were told: "Next you will see profiles of the three other participants who will work with you.". After seeing the profiles of three others' profiles with pass port size photos, participants started the PGG. For each round, participants were presented with round $\mathrm{N}$ first. Next, participants were required to decide how many of their 20 tokens to contribute to group pot. While participants were required to decide on how many of their 20 tokens to contribute, the three others' players' pictures were also presented. After they had made their decision, they entered their choice into the computer. Next, they were required to wait between 4000 to $12000 \mathrm{~ms}$, as randomly determined by the program. Then feedback was presented, including "Other people contributed tokens: (the sum of three other players' contribution), Your contribution this round is: (the number of tokens they contributed), Your share of the pot for this round: (the number of tokens they received from the pot), Your total number of tokens on this round: (the total number of tokens they will receive on that round), and Your cumulative total of tokens across rounds: (the total number of tokens they will receive across all rounds)". Participants were required to copy down those values into the form using pencil and paper provided. The reason for this was to make sure that participants attended to all the feedback information presented on screen on each round. When they completed the round, they were required to press the spacebar to continue to the next round. This procedure was repeated until all 10 rounds were complete.

On completion of the PGG, participants were then presented with the post-questions, which includes self-report empathizing and similarity. Moreover, IRI was followed. Finally, there were debriefing questions, in which they we re informed in detail about the study its purpose.

\section{Scoring}

With regards to scoring for the IRI empathy questionnaire, the four subscales (PT, PD, FS and EC) were scored individually. Each subscale consisted of 7 items; with some items were reverse scoring (item 3, 4, 7, 12, 13, 14, 15, and 
19). Specifically, PT comprised items $3,8,11,15,21,25,28$; PD comprised items 6, 10, 13, 17, 19, 24 and 27; FS comprised items 1, 5, 7, 12, 16, 23 and 26; EC comprised items 2, 4, 9, 14, 18, 20 and 22. Similarity and Empathizing were scored according to the rating in the post-questions, ranged from 1 (not at all) to 9 (very much).

\section{RESULTS}

We first reported the self-report similarity and empathizing degree in four conditions, then differences between contributing proportion, and then tit-for-tat strategy in each condition. A regression analysis examined the potential association between first round's contribution in the PGG and dis positional empathy ability.

\section{Self-report Empathy and Similarity}

To begin with, we examined if there were group differences based on self-report similarity and self-report empathy of participants' personal values and those of the three other players in Social Value and Economic Value conditions. There were no significantly different for the self-report similarity amongst the four conditions. In tems of self-report empathy based on those profiles, the interaction between value and empathy was significant, which suggested that in the high empathy condition, the self-report empathy in Economic Value condition $(M=5,09, S D=17.63)$ is significantly lower than the Social Value condition ( $M=6.33, S D=17.63), F(1,116)=7.48, p=.007, \eta_{p}{ }^{2}=.061$.

\section{PGG: First round}

In the first round, the mean of contribution rate was $0.52(\mathrm{SD}=0.30), 95 \% \mathrm{Cl}[0.47,0.58]$, which located at the interval of $40 \% \sim 60 \%$ of the overall personal endowments. At this stage in the PGG $(\mathrm{N}=120)$, the value manipulation did not impact on the number of tokens contributed, $\left.F(1,116)=.435, p=.511, \eta_{p}^{2}=.004\right)$, and neither did the induction of empathy, $F(1$, $\left.116)=2.89, \mathrm{p}=.09, \mathrm{n}_{\mathrm{p}}{ }^{2}=.024\right)$. There was also no significant interaction between value and empathy on first round contributions, $\left.\mathrm{F}(1,116)=0.001, \mathrm{p}=.99, \mathrm{n}_{\mathrm{p}}^{2}<.0001\right)$.

\section{PGG: All rounds}

\section{Value Manipulation}

To examine the main manipulations of the study, we entered all data's $(N=120)$ individual contributions made in each round by each participant into a $2 \times 2 \times 2 \times 10$ (value [Social Value, Economic Value] $\times$ empathy [Empathy, No Empathy] $\times$ Deception [Deception Success condition, Deception Failure condition] as the between-subject variables $\times$ round [Round $1-10]$ as the within-subject variable) mixed ANOVA. The Mauchly's test indicated that the assumption of sphericity had been violated, $X 2(44)=166.63, p<.001$, therefore Greenhouse-Geisser corrected tests were reported $(\varepsilon=.71)$.

Table 1A shows the mean contribution in each of the four conditions. The analyses revealed that only for 10 round $\times$ value $\times$ empathy $\times$ Deception four-way interaction was significant, $F(6.42,712.38)=55.95, p=.059, \eta_{p}^{2}=.018$. Apart from that all were non-significant. Thus, we classified each participant according to whether they believed they were interacting with three other players online into Deception Success group and Deception Failure group for further analysis.

In terms of Deception Success group $(n=70)$, a $10 \times 2 \times 2$ (round [Round 1-10] $\times$ value [Social Value, Economic Value] $\times$ empathy [No Empathy, Empathy]) repeated measures ANOVA was conducted. As shown in Table 1B, the results showed that the interaction between value $\times$ empathy was significant, $F(1,66)=6.782, p=.011, \eta_{p}^{2}=.093$. Statistic power was calculated by $G^{*}$ power (http://www.gpower.hhu.de/en.html), $(1-\beta=1.00>.80)$. Painwise comparison showed that in Empathy condition, there was significant difference between Economic Value condition and Social Value condition, $p$ $=.004, \eta_{p}^{2}=.118$; not found in the No Empathy condition, $p=.736, \eta_{p}^{2}=.002$, which indicated that when there was empathy induction, for those presented Social Values stories contributed more than those communicated Economic Values.

Table 1A The Mean Contribution for the Four Conditions $(\mathrm{N}=120)$

\begin{tabular}{|c|c|c|c|c|c|c|}
\hline \multirow{2}{*}{ Value } & \multicolumn{3}{|c|}{ No Empathy } & \multicolumn{3}{c|}{ Empathy } \\
\cline { 2 - 7 } & $\mathrm{M}(\mathrm{SD})$ & $\mathrm{n}$ & $95 \% \mathrm{Cl}$ & $\mathrm{M}(\mathrm{SD})$ & $\mathrm{n}$ & $95 \% \mathrm{Cl}$ \\
\hline Economic Values & $9.95(4.86)$ & 30 & {$[8.19,11.71]$} & $6.47(7.61)$ & 30 & {$[3.73,9.23]$} \\
& & & & & & \\
\hline Social Values & $9.53(4.39)$ & 30 & {$[7.94,11.13]$} & $9.82(3.93)$ & 30 & {$[8.40,11.24]$} \\
\hline
\end{tabular}

Table 1B The Mean Contribution for those Deception Success Group $(n=70)$

\begin{tabular}{|c|c|c|c|c|c|c|}
\hline \multirow{2}{*}{ Value } & \multicolumn{3}{|c|}{ No Empathy } & \multicolumn{3}{c|}{ Empathy } \\
\cline { 2 - 7 } & $\mathrm{M}(\mathrm{SD})$ & $\mathrm{n}$ & $95 \% \mathrm{Cl}$ & $\mathrm{M}(\mathrm{SD})$ & $\mathrm{n}$ & $95 \% \mathrm{Cl}$ \\
\hline Economic values & $9.44(3.00)$ & 24 & {$[8.21,10.66]$} & $6.73(4.25)$ & 22 & {$[4.92,8.54]$} \\
\hline Social values & $9.14(2.04)$ & 11 & {$[7.86,10.42]$} & $10.38(3.00)$ & 13 & {$[8.71,12.04]$} \\
\hline
\end{tabular}


Table 1C The Mean Contribution for those Deception Failure Group $(n=49)$

\begin{tabular}{|c|c|c|c|c|c|c|}
\hline \multirow{2}{*}{ Value } & \multicolumn{3}{|c|}{ No Empathy } & \multicolumn{3}{c|}{ Empathy } \\
\cline { 2 - 7 } & $\mathrm{M}(\mathrm{SD})$ & $\mathrm{n}$ & $95 \% \mathrm{Cl}$ & $\mathrm{M}(\mathrm{SD})$ & $\mathrm{n}$ & $95 \% \mathrm{Cl}$ \\
\hline Economic values & $10.47(4.91)$ & 6 & {$[6.42,14.51]$} & $9.71(4.90)$ & 17 & {$[7.31,12.11]$} \\
\hline Social values & $9.93(4.91)$ & 8 & {$[6.43,13.43]$} & $9.37(4.91)$ & 18 & {$[7.04,11.71]$} \\
\hline
\end{tabular}

The analys is also found that the interaction between round $x$ empathy was marginally significant, $F(6.24,411.86)$ $=1.92, p=.073, \eta_{p}^{2}=.028,(1-\beta=.976>.80)$. The main effect of round was significant, $F(6.24,411.86)=9.98, p<.001$, $\eta_{p}^{2}=.13,(1-\beta=1.00>.80)$.

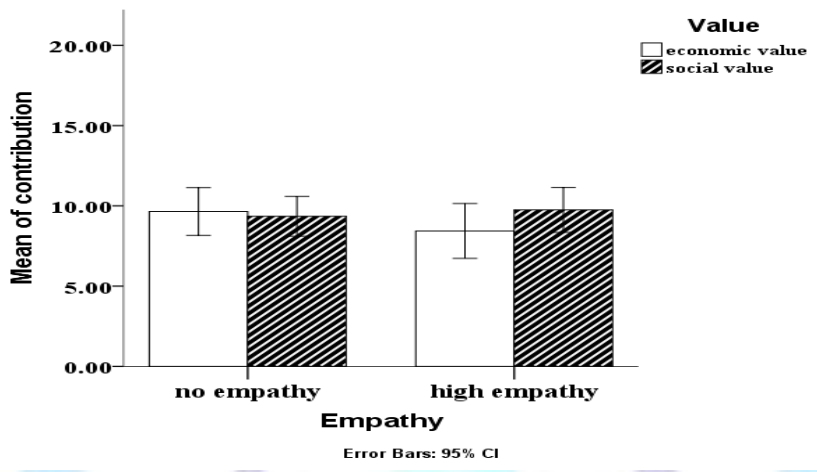

Figure 1A. Average contributions in four conditions for the All data ( $N=120)$
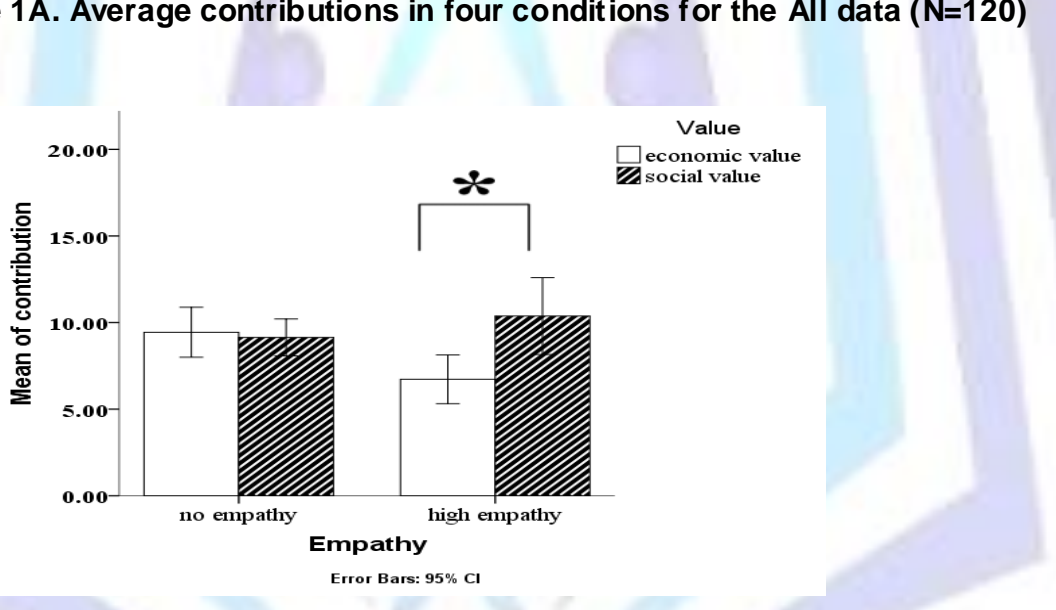

Figure 1B. Average contributions in four conditions for Deception Success group $(n=70)$

Turning now to the Deception Failure group $(n=49)$, while it is hard to interpret the behavior, their pattern of contributions does provide some insights. In the present study, the tokens at the end of PGG converted into real money for our participants. Therefore rationally, the Deception Failure group should consistently make zero contributions in every round, because pro-sociality is dis-incentivized since they believe they are not interacting with real players. However, the social nature of the PGG set up appears to have encouraged the Deception Failure group to contribute reliably above zero ( $\mathrm{M}=$ $9.71, \mathrm{SD}=4.77, \mathrm{t}(48)=14.25, \mathrm{p}<.001)$, as we can see from Table 1C. A repeated measures ANOVA was performed on the Deception Failure group across 10 round PGG and 1st round PGG data, none of interactions and main effect were significant.

\section{Tit-for-tat strategy}

To test the effect of main manipulation (empathy \& values) on tit-for-tat strategy, A logic linear analysis were performed on the number of participants using the strategy in each conditions. Prior studies suggest that the tit-for-tat strategy is a common strategy employed in social dilemmas such as the PGG. Therefore we correlated the contributions of the participants from 2 nd to the 10th round with the mean contributions of the three other players' from 1st to 9th round. A significant correlation between participants' contributions and those of the other players was classified as tit-for-tat strategy, and anything non-significant was classified as other strategy. Table 2 showed the number and proportion of people using tit-for-tat strategy in each condition. A log-linear analysis revealed more participants were classified as using the tit-for-tat strategy in the No Empathy condition as compared to the Empathy condition, $Z=2.815, p=.005$. (N=120); $Z$ $=2.926, p=.040(n=70)$. While the empathy induction manipulation did not lead to increases overall in the contributions made in the PGG, it did affect the types of strategies that participants employed and discouraged tit-for-tat usage. 
Table 2A The Number and Proportion Using Tit-for-tat Strategy in Four Conditions (Value $\times$ Empathy) $(\mathrm{N}=120)$

\begin{tabular}{|c|c|c|}
\hline Value & No Empathy & Empathy \\
\hline Economic Values & $11 / 30(36.67 \%)$ & $5 / 30(16.67 \%)$ \\
\hline Social Values & $11 / 30(36.67 \%)$ & $3 / 30(10 \%)$ \\
\hline
\end{tabular}

Table 2BThe Number and Proportion Using Tit-for-tat Strategy in Four Conditions (Value $\times$ Empathy) $(n=70)$

\begin{tabular}{|c|c|c|}
\hline Value & No Empathy & Empathy \\
\hline Economic Values & $10 / 24(41.67 \%)$ & $2 / 11(18.18 \%)$ \\
\hline Social Values & $10 / 22(45.45 \%)$ & $2 / 13(15.38 \%)$ \\
\hline
\end{tabular}

\section{Regression between PGG and Empathic disposition}

To test the individual difference effect of empathy on contribution rate in PGG, a Linear Regression analysis was carried out on the first round contribution, age and the score of subscales (PT, PD, FS, EC) of IRI. As we can see from Table 3 , none of subscales of IRI did predict the first round contribution in the PGG for the Deception Success group.

Table 3 Summary of Hierarchical Regression Analysis for Variables Prediction Contribution in First Round of PGG ( $=70)$

\begin{tabular}{|c|c|c|c|c|}
\hline Variables & B & SEB & $\square \square$ & $\square$ 95\% Cl \\
\hline Step 1 & & & & \\
\hline Age & -.051 & .202 & -.037 & {$[-.458, .355]$} \\
\hline Step 2 & & & & \\
\hline Age & -.131 & .250 & -.094 & {$[-.636, .374]$} \\
\hline PT & .938 & .806 & .186 & {$[-.688,2.564]$} \\
\hline PD & -.346 & .745 & -.079 & {$[-1.848,1.156]$} \\
\hline FS & .105 & .648 & .026 & {$[-1.202,1.413]$} \\
\hline EC & -.1 .342 & 1.471 & -.197 & {$[-4.308, .1 .625]$} \\
\hline
\end{tabular}

Note. $R^{2}=.001$ for step $1 ; \Delta R^{2}=.0054$ for step $2 .{ }^{*} p<.05$;

\section{DISCUSSION}

Typically in face-to-face interactions in the real world social pressures and social noms, along with multiple verbal, nonverbal cues are likely to have a significant impact on sustaining or even increasing pro-social behaviors (45). The aim of the present study was to examine potential relevant cues that could influence a specific pro-social behavior, namely cooperation, in an online interactive social dilemma game (PGG). To this end, we found that values, for those that believed that they were interacting with real players online, did impact on prosocial behaviors in the PGG. In particular, when participants were interacting with players that were revealed to have predominately social values, contributions were higher than those interacting with players that had mostly economic values. This supports our main prediction. We also speculated that the role of empathy might not play a significant role in online interactions. Consistent with this, our empathy induction manipulation did not lead to increases in cooperation relative to the No Empathy condition, but it did impact on the types of strategies that were employed in the PGG.

First, in terms of our empathy manipulation, while consistent with our speculations, the present results are inconsistent with many previous studies $(6,22,28)$ that use social dilemmas such as the prisoner's dilemma. Our empathy manipulation was identical to other studies that have demonstrated enhanced effects on pro-social behaviors, which is why it is more likely that the mixed findings are a result of differences concerning the PGG procedures, rather than the fact that empathy per se is less effective as an emotional cue when interacting online. In the present study participants were asked to decide the amount of tokens they would contribute to the group pot, whereas in previous studies participants could decide to contribute their tokens to a group pot, or an individual player. This may be a critical difference, because in C. D. Batson et al.'s study(27), when empathy was induced, participants increased their cooperation for the target player they most empathized with, which was not possible in the present study. Nevertheless, in the present study, we present participants with details of players that had personal experiences that they could empathize with, so they could reveal their pro-social tendencies by cooperating more overall. While empathy did not reveal itself in cooperative behaviors per se, those induced to empathize were less likely to use tit-for-tat strategy. Tit-for-tat is a strategy that is often relied on as an efficient and defensive means of guarding against betrayal of pro-sociality (46). It may be the case that empathy may not have induced cooperation; it did however reduce the uptake of an obvious tit-for-tat strategy, which is typically employed as a defensive or efficient non-pro-social strategy. Moreover, our study explored dispositional empathy ability as a predictor of first round contributions in the PGG. However, we only found weak evidence for a connection between. Again, this may be the result of the procedures we used in our PGG, or because there is an unstable association between empathy and cooperation when interacting with others online.

Second, the present study did find evidence to suggest that signalling pro-social behavioral dispositions online is a useful cue that participants use to determine the extent to which they cooperate, consistent with Parks' Integrated Model (23). As previous work has shown, if one is provided with information that reveals pro-social behaviors such as trustworthiness (47), cooperative behavior with strangers increases. While this study is the first of its kind to provide evidence of the 
mediating role of values in a linear PGG, it lends further supports the work of Volk et al. (39)which suggested that values do play a role in cooperation. One question our findings raise is what role values play for determining cooperative behaviors in the PGG. Given that the overall pattern of contributions decays over rounds, which is consistent with previous studies of PGG (10), one way of conceptualising the role of values is that signalling social values reduced decay relative to signalling economic values. Thus, the findings from the present study lim it claims that signalling materialistic values per se is a way of increasing cooperation overall, at least for the linear PGG. In order to support this claim, further studies using the PGG would have to show that participants (either interacting with real or virtual players) make higher contributions systematically across rounds when not providing any information in contrast to providing information signalling economic values.

The present study used real financial incentives rather the fixed payments or credits, in line with standard economic versions of the linear PGG based on recommendations by economists and psychologists (48). However this study introduced a form of social-interaction-deception, because participants were led to believe they were interacting with real players. Although this was present, our findings suggest that, compared with other studies, overall, first round contributions were within the standard $40 \%-60 \%$ range of endowments (10), which suggest that the decision-making behavior we observed was in line with previous economic studies that involve genuine (though typically not direct face-toface) interactions with real players. Nevertheless, to examine the impact of social-interaction-deception on decisionmaking behavior we asked participants if they did indeed believe they were interacting with real players, and only a small proportion did not. What is curious is that these participants continued to make contributions knowing that they were not interacting with real players, when the rational strategy would be to contribute nothing on each round. One explanation for this is that participants were subject to social desirability bias, which is the tendency to present oneself in a positive social manner to be accepted by others $(49,50)$. Despite this, the vast majority of participants, in our study $58 \%$, who indicated that they believed they were genuinely interacting with real players, revealed systematic patterns of behavior consistent with our predictions. Nevertheless, future studies that include manipulations such as the ones used here should include checks to identify if participants are aware of the presence of deception, whatever kind is used.

\section{CONCLUSION}

Overall, in an online interactive setup, we showed that signals of social values as compared to economic values maintained cooperation in a social dilemma when there were perspective-taking instructions. Moreover, empathy reduced the likelihood of a typical reciprocal strategy (tit-for-tat). We propose that for online social interactions people rely more on different cues than when they are interacting with in real face-to-face settings.

\section{ACKNOWLEDGMENTS}

We thank Sadia Osmany for contributing to part of data collection for this study. We also extremely appreciate Agata Ryterska, Vera Sarkol, Jayden Van Horik for devoting their photos as the three fictitious players' pictures. This research was supported by the China Scholarship Council (CSC201206990009).

\section{REFERENCES}

[1] lannotti RJ.1985. Naturalistic and structured assessments of prosocial behavior in preschool children: The influence of empathy and pers pective taking. Developmental Psychology 21(1):46-55.

http://dx.doi.org/10.1037/0012-1649.21.1.46

[2] Hogg T \& Huberman BA.1992. Better than the best: The power of cooperation. SFI:163-184.

http://www.researchgate.net/profile/Tad Hogg/publication/2847868 Better Than The Best The Power of Coo peration/links/0046351758180a105a000000.pdf

[3] Schalk R, Curseu PL, Schalk R, \& Curseu PL.2010. Cooperation in organizations. Journal of Managerial Psychology 25(5):453-459. http://dx.doi.org/10.1108/02683941011048364

[4] Galimberti C, Ignazi S, Vercesi P, \& Riva G.2001. Communication and cooperation in networked environments: An experimental analysis. CyberPsychology \& Behavior 4(1):131-146. http://online.liebertpub.com/doi/abs/10.1089/10949310151088514

[5] Wilson RK, Stevens on R, \& Potts G.2006. Brain activity in the play of dominant strategy and mixed strategy games. Political Psychology 27(3):459-478. http://onlinelibrary.wiley.com/doi/10.1111/j.1467$\underline{9221.2006 .00510 . x / a b s t r a c t}$

[6] Batson CD \& Moran T.1999. Empathy-induced altruism in a prisoner's dilemma. European Joumal of Social Psychology 29(7):909-924. http://onlinelibrary.wiley.com/doi/10.1002/(SICI)10990992(199911)29:7\%3C909::AID-EJSP965\%3E3.0.CO;2-L/abstract?TB iframe=true\&width=921.6\&height=921.6 Has elhuhn MP \& Mellers BA.2005. Emotions and cooperation in economic games. Cognitive Brain Research 23(1):24-33. http://www.ncbi.nlm.nih.gov/pubmed/15795131

[8] Sanfey AG, Rilling JK, Aronson JA, Nystrom LE, \& Cohen JD.2003. The neural bas is of economic decisionmaking in the ultimatum game. Science 300(5626):1755-1758.

http://www.sciencemag.org/content/300/5626/1755.short

[9] Fehr E \& Gächter S.2000. Cooperation and punis hment in public goods experiments. Institute for Empirical Res earch in Economics Working Paper (10). http://papers.ss rn.com/sol3/papers.cfm ?abstract id=203194

[10] Ledyard JO.1994. Public goods: A survey of experimental research. Public Economics. https://ideas.repec.org/p/cla/levarc/509.html

[11] Budescu DV \& Au WT.2002. A model of sequential effects in common pool resource dilemmas. Journal of Behavioral Decision Making 15(1):37-63. http://onlinelibrary.wiley.com/doi/10.1002/bdm.402/abstract 


\section{ISSN 2321-1091}

[12] van Dijk E, Wilke H, \& Wit A.2003. Preferences for leadership in social dilemmas: Public good dilemmas versus common resource dilemmas. Joumal of Experimental Social Psychology 39(2):170-176.

http://www.sciencedirect.com/science/article/pii/S0022103102005188

[13] Fehr E \& Fischbacher U.2004. Social noms and human cooperation. Trends in cognitive sciences 8(4):185-190. http://www.ncbi.nlm.nih.gov/pubmed/15050515

[14] Komorita SS \& Parks CD.1995. Interpersonal relations: Mixed-motive interaction. Annual review of psychology 46(1):183-207. http://www.scopus.com/inward/record.url?eid=2-s2.0-

11944253809\&partnerlD=40\&m d5=de6d8e4335e1c3ff6e824972f3343238

[15] Axelrod R \& Hamilton WD.1981. The evolution of cooperation. Science 211(4489):1390-1396.

http://www.sciencemag.org/content/211/4489/1390.short

[16] Nowak M \& Sigmund K.1993. A strategy of win-stay, lose-shift that outperforms tit-for-tat in the Prisoner's Dilemma game. Nature 364(6432):56-58. http://dx.doi.org/10.1038/364056a0

[17] Axelrod R.1984. The evolution of cooperation (Basic Books, Inc., New York)

[18] Levine LE \& Hoffman ML.1975. Empathy and cooperation in 4-year-olds. Developmental Psychology 11(4):533534. http://search.ebscohost.com/login .aspx?direct=true\&db=pdh\&AN=1975-25043-001\&site=ehost-live

[19] Cohen TR, Wildschut T, \& Insko CA.2010. How communication increases interpersonal cooperation in mixedmotive situations. Journal of Experimental Social Psychology 46(1):39-50.

http://www.sciencedirect.com/science/article/pii/S0022103109002303

[20] De Cremer D.1999. Trust and fear of exploitation in a public goods dilemma. Current Psychology $18(2): 153-163$. http://link.springer.com/article/10.1007/s 12144-999-1024-0

[21] Batson CD \& Ahmad N.2001. Empathy-induced altruism in a prisoner's dilemma II: what if the target of empathy has defected? European Joumal of Social Psychology 31(1):25-36.

http://onlinelibrary.wiley.com/doi/10.1002/ejsp.26/abstract

[22] Rumble AC, Van Lange PAM, \& Parks CD.2010. The benefits of empathy: When empathy may sus tain cooperation in social dilemmas. European Joumal of Social Psychology 40(5):856-866.

http://dx.doi.org/10.1002/ejsp.659

[23] Parks CD, Joireman J, \& Van Lange PAM.2013. Cooperation, trust, and antagonism how public goods are promoted. Psychological Science in the Public Interest 14(3):119-165. http://psi.sagepub.com/content/14/3/119.abstract

[24] Kelley HH \& Thibaut JW.1978. Interpers onal relations: A theory of interdependence (Wiley, New York)

[25] Peñarroja V, Orengo V, Zornoza A, \& Hernández A.2013. The effects of virtuality level on task-related collaborative behaviors: The mediating role of team trust. Computers in Human Behavior 29(3):967-974. http://www.sciencedirect.com/science/article/pii/S0747563212003603

[26] Batson CD.1991. The altruism question: Toward a social psychological answer (Lawrence Erlbaum, New York, NY)

[27] Batson CD, et al.1995. Empathy and the collective good: Caring for one of the others in a social dilemma. Journal of Pers onality and Social Psychology 68(4):619-631. http://dx.doi.org/10.1037/0022-3514.68.4.619

[28] Xu H, Kou Y, \& Zhong N.2012. The effect of empathy on cooperation, forgiveness, and "Returning Good for Evil" in the prisoner's dilemma. Public Personnel Management 41(5):105-115.

http://ppm.sagepub.com/content/41/5/105.s hort

[29] Bilsky W \& Schwartz SH.1994. Values and personality. European Joumal of Personality 8(3):163-181. http://onlinelibrary.wiley.com/doi/10.1002/per.2410080303/abstract

[30] Vernon P, E., \& Allport GW.1931. A test for personal values. The Journal of Abnormal and Social Psychology. http://dx.doi.org/10.1037/h0073233

[31] Olver JM \& Mooradian TA.2003. Personality traits and personal values: a conceptual and empirical integration. Personality and Individual Differences 35(1):109-125.

http://www.sciencedirect.com/science/article/pii/S0191886902001459

[32] Parks L \& Guay RP.2009. Personality, values, and motivation. Personality and Individual Differences 47(7):675684. http://www.sciencedirect.com/science/article/pii/S0191886909002529

[33] Bardi A\& Schwartz SH.2003. Values and behavior: Strength and structure of relations. Personality and social psychology bulletin 29(10):1207-1220. http://psp.sagepub.com/content/29/10/1207.short

[34] Schwartz SH \& Huismans S.1995. Value priorities and religiosity in four western religions. Social Psychology Quarterly:88-107. http://www.jstor.org/stable/2787148?seq=1-page scan tab contents

[35] Probst TM, Carnevale PJ, \& Triandis HC.1999. Cultural values in intergroup and single-group social dilemmas. Organizational behavior and human decision processes 77(3):171-191. http://www.sciencedirect.com/science/article/pii/S0749597899928224

[36] Simpson B.2004. Social Values, Subjective Transfomations, and Cooperation in Social Dilemmas. Social Psychology Quarterly 67. http://spq.sagepub.com/content/67/4/385.short

[37] Balliet D, Parks C, \& Joireman J.2009. Social value orientation and cooperation in social dilemmas: A metaanalysis. Group Processes \& Intergroup Relations 12(4):533-547. http://gpi.sagepub.com/content/12/4/533.short

[38] Bogaert S, Boone C, \& Declerck C.2008. Social value orientation and cooperation in social dilemmas: A review and conceptual model. British Journal of Social Psychology 47(3):453-480.

http://onlinelibrary.wiley.com/doi/10.1348/014466607X244970/abstract

[39] Volk S, Thöni C, \& Ruigrok W.2011. Personality, personal values and cooperation preferences in public goods games: A longitudinal study. Personality and Individual Differences 50(6):810-815.

http://www.s ciencedirect.com/science/article/pii/S0191886911000043 


\section{ISSN 2321-1091}

[40] Rand DG, Greene JD, \& Nowak MA.2012. Spontaneous giving and calculated greed. Nature 489(7416):427-430. http://www.ncbi.nlm.nih.gov/pubmed/22996558

[41] Kurzban R \& Houser D.2005. Experiments investigating cooperative types in humans: a complement to evolutionary theory and simulations. Proceedings of the National Academy of Sciences 102(5):1803-1807. http://www.ncbi.nlm.nih.gov/pubmed/15665099

[42] Keltner D, Kogan A, Piff PK, \& Saturn SR.2014. The Sociocultural Apprais als, Values, and Emotions (SAVE) Framework of Prosociality: Core Processes from Gene to Meme. Annual review of psychology 65:425-460. http://www.annualreviews .org/doi/abs/10.1146/annurev-psych-010213-115054

[43] Davis MH.1983. Measuring individual differences in empathy: Evidence for a multidimensional approach. Journal of Personality and Social Psychology 44(1):113-126.

http://search.ebscohost.com/login.aspx?direct=true \&db=pdh\&AN=1983-22418-001\&site=ehost-live

[44] Osman M.2014. What are the essential cognitive requirements for prospection (thinking about the future)? Front Psychol 5:626. http://www.ncbi.nlm.nih.gov/pubmed/25071625

[45] Singer T \& Steinbeis N.2009. Differential Roles of Fairness - and Compassion- Based Motivations for Cooperation, Defection, and Punishment. Annals of the New York Academy of Sciences 1167(1):41-50. http://onlinelibrary.wiley.com/doi/10.1111//.1749-

6632.2009.04733.x/abstract?us erls Authenticated=false\&deniedAccessCus tom isedMessage $=$

[46] Komorita SS, Parks C, \& Hulbert L.1992. Reciprocity and the induction of cooperation in social dilemmas. Journal of Personality and Social Psychology 62(4):607. http://dx.doi.org/10.1037/0022-3514.62.4.607

[47] Stave JA.1983. The relationship between empathic dentist behavior and children's cooperation. Journal of Dental Education 47(8):555-557. http://eric.ed.gov/?id=EJ286798

[48] Hertwig R \& Ortmann A.2001. Experimental practices in economics: A methodological challenge for psychologists? Behavioral and Brain Sciences 24(03):383-403.

http://journals .cambridge.org/action/dis playAbstract? fromPage=online\&aid=88683\&fileld=S0140525X01004149

[49] Edwards AL.1957. The social desirability variable in personality assessment and research (Dryden Press, US).http://psycnet.apa.org/psycinfo/1958-00464-000

[50] King MF \& Bruner GC.2000. Social desirability bias: A neglected aspect of validity testing. Psychology and Marketing 17(2):79-103. http://dx.doi.org/10.1002/(SICI)1520-6793(200002)17:2\%3C79::AIDMAR2\%3E3.0.CO;2-0

\section{Author' biography with Photo}

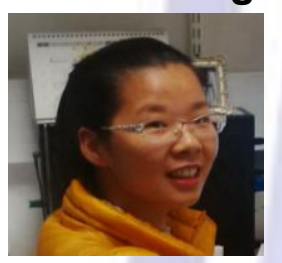

Jieyu LV is a PhD candidate in Experimental Psychology in the Dynamic Learning \& Decision Making Lab (DLDM) in Queen Mary University of London, UK.

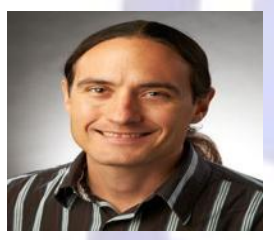

Dr. Michael Proulx isa Senior Lecturer in the Department of Psychology at the University of Bath, and Head of the Crossmodal Cognition Laboratory.

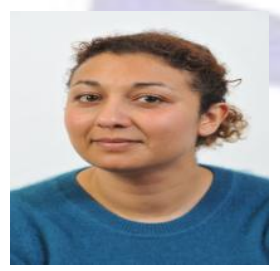

Dr. Magda Osman is a Senior Lecturer in Experimental Cognitive Psychology at Queen Mary University of London, and Head of the Dynamic Learning \& Decision Making Laboratory (DLDM).

\section{APPENDIX}

\section{Appendix 1. Interpersonal Reactivity Index (Davis, 1983)}

The following statements inquire about your thoughts and feelings in a variety of situations. For each item, indicate how well it describes you by choosing the appropriate letter on the scale at the top of the page: $1,2,3,4$, or 5 . When you have decided on your answer, fill in the letter on the answer sheet next to the item number. READ EACH ITEM CAREFULLY BEFORE RESPONDING. Answer as honestly as you can. Thank you. ANSWER SCALE:

$\begin{array}{llll}1 & 3 & 4 & 5 \\ \text { DOES NOT } & & & \text { DESCRIBES ME } \\ \text { DESCRIBE ME } & & & \text { VERY } \\ \text { WELL } & & \text { WELL }\end{array}$


1. I daydream and fantasize, with some regularity, about things that might happen to me. (FS)

2. I often have tender, concerned feelings for people less fortunate than me. (EC)

3. I sometimes find it difficult to see things from the "other guy's" point of view. (PT) (-)

4. Sometimes I don't feel very sorry for other people when they are having problems. (EC) (-)

5. I really get involved with the feelings of the characters in a novel. (FS)

6. In emergency situations, I feel apprehensive and ill-at-ease. (PD)

7. I am usually objective when I watch a movie or play, and I don't often get completely caught up in it. (FS) (-)

8. I try to look at e verybody's side of a disagreement before I make a decision. (PT)

9. When I see someone being taken advantage of, I feel kind of protective towards them. (EC)

10. I sometimes feel helpless when I am in the middle of a very emotional situation. (PD)

11. I sometimes try to understand my friends better by imagining how things look from their perspective. (PT)

12. Becoming extremely involved in a good book or movie is somewhat rare for me. (FS) (-)

13. When I see someone get hurt, I tend to remain calm. (PD) (-)

14. Other people's misfortunes do not usually disturb me a great deal. (EC) $(-)$

15. If I'm sure I'm right about something, I don't waste much time listening to other people's arguments. (PT) (-)

16. After seeing a play or movie, I have felt as though I were one of the characters. (FS)

17. Being in a tense emotional situation scares me. (PD)

18. When I see someone being treated unfairly, I sometimes don't feel very much pity for them. (EC) (-)

19. I am usually pretty effective in dealing with emergencies. (PD) (-)

20. I am often quite touched by things that I see happen. (EC)

21. I believe that there are two sides to every question and try to look at them both. (PT)

22. I would describe myself as a pretty soft-hearted person. (EC)

23. When I watch a good movie, I can very easily put myself in the place of a leading character. (FS)

24. I tend to lose control during emergencies. (PD)

25. When I'm upset at someone, I usually try to "put myself in his shoes" for a while. (PT)

26. When I am reading an interesting story or novel, I imagine how I would feel if the events in the story were happening to me. (FS)

27. When I see someone who badly needs help in an emergency, I go to pieces. (PD)

28. Before criticizing somebody, I try to imagine how I would feel if I were in their place. (PT)

NOTE: (-) denotes item to be scored in reverse fashion (6 minus their scoring)

$\mathrm{PT}=$ perspective-taking scale

$\mathrm{PD}=$ personal distress scale

$\mathrm{FS}=$ fantasy scale

$E C=$ empathic concern scale

\section{Appendix 2. Three pairs value stories}

Social value stories: (Family, Friends, Health)

Family

My grandfather had an operation recently. I went to visit him in hospital whenever I could. It has been worrying because I am really close to him and it's been very stressful and emotion for me and my family. But he is recovering now. Friends

I speak to my best friend nearly every day. She is the closest person to me outside of my family. Recently we fell out. This isn't the first time that this has happened, and I know that we can fix this, but it is still upsetting.

Health

I was riding my bicycle down the main road lastmonth. I lost control and crashed into a lamppost. The bike didn't flip, thankfully, but my arm was severely injured. I had to go to hospital, and they put my arm in a sling. It took me approximately 3 weeks to recover.

\section{Economic value stories (Pet, Phone, Bicycle) \\ Pet}

My pet dog Scruffy had an operation recently. I went to visit him at the vets whenever I could. It has been worrying because I am really close to him and it's been very stressful and emotion for me and my family. But he is recovering now. Phone

I speak on my mobile phone nearly every day. It is the object most close to me other than my laptop. Recently I broke my phone. It fell out of my bag. This isn't the first time that this has happened, and I know that I can fix this, but it is sti ll upsetting.

Bicycle

I was riding my bicycle down the main road last month. I lost control and crashed into a lamppost. The bike didn't flip, but unfortunately it did get bust up. I had to take it into the repair shop, because it was seriously damaged. It took approximately 3 weeks to get fixed. 